\title{
Influence of the Injection Site on the Pharmacokinetics of Cefquinome Following Intramuscular Injection in Piglets
}

\author{
In Bae SONG ${ }^{1)}$, Tae Won KIM ${ }^{1)}$, Hong Gee LEE ${ }^{1}$, Myoung Seok KIM²), Youn Hwan HWANG ${ }^{3)}$, Byung Kwon PARK ${ }^{1)}$, \\ Jong Hwan LIM $^{4)}$ and Hyo In YUN ${ }^{1) *}$ \\ 1) Laboratory of Veterinary Pharmacology and Toxicology, College of Veterinary Medicine, Chungnam National University, Daejeon \\ 305-764, South Korea \\ 2) Jeollanamdo Development Institute for Traditional Korean Medicine, Jangheung-gun 529-851, South Korea \\ ${ }^{3)}$ Korea Institute of Oriental Medicine, Daejeon 305-811, South Korea \\ 4) B\&C Biopharm, Advanced Institutes of Convergence Technology, Suwon-si 443-759, South Korea
}

(Received 6 May 2012/Accepted 2 August 2012/Published online in J-STAGE 10 August 2012)

ABSTRACT. The aim of the present study was to investigate the influence of different injection sites, i.e., the neck area and thigh muscle, on the pharmacokinetics of cefquinome in piglets following intramuscular (i.m.) injection. Cross-bred (Landrace $\times$ Duroc $\times$ Yorkshire) piglets were administered the same dose of cefquinome $(2 \mathrm{mg} / \mathrm{kg}$ body weight $)$ via intravenous injection and intramuscular injection into the neck area or thigh. The mean maximum concentrations $\left(\mathrm{C}_{\max }\right)$ of cefquinome following i.m. injection into neck or thigh area were 4.62 $\pm 0.31 \mu \mathrm{g} / \mathrm{m} l$ at $0.38 \pm 0.14 \mathrm{hr}$ and $4.39 \pm 0.53 \mu \mathrm{g} / \mathrm{ml}$ at $0.42 \pm 0.13 \mathrm{hr}$, respectively. The absolute bioavailabilities (F) of cefquinome after i.m. injection into the neck or thigh area were $103.04 \pm 13.01$ and $97.56 \pm 16.14 \%$, respectively $(P>0.05)$. There were no differences noted between the two different injection sites for the pharmacokinetic properties of cefquinome after i.m. injection in piglets. Further studies will be needed to determine the incidence or severity of injection site reactions following repeated administrations of cefquinome into both injection sites.

KEY WORDS: cefquinome, injection site, intramuscular injection, pharmacokinetic.

doi: 10.1292/jvms.12-0201; J. Vet. Med. Sci. 75(1): 89-92, 2013

Cefquinome, an aminothiazolyl cephalosporin, is a fourth-generation cephalosporin that has been used employed for veterinary use only [14]. It has broad-spectrum antibacterial activity against clinically important bacteria such as Streptococcus spp., Staphylococcus spp., Pseudomonas spp., Moraxella spp., Haemophilus spp. and grampositive anaerobes $[9,13,15,16]$. Cefquinome is highly stable in the presence of $\beta$-lactamases produced by many clinically important bacteria [17]. It has been approved for the treatment of respiratory diseases in pigs, respiratory tract diseases, acute mastitis and foot rot in cattle, calf septicemia and metritismastitis-agalactia syndrome in sows [3, 4]. The pharmacokinetics of cefquinome have been reported in mice, horses, cattles, rabbits and ducks [6, 10, 13, 20, 21]. Cefquinome has several favorable pharmacokinetic features, such as good absorption, high bioavailability and direct elimination via the kidney.

The rate and extent of drug absorption following its intramuscular (i.m.) or subcutaneous (s.c.) injection depends on the drug's physicochemical properties, the injection volume and the pharmaceutical preparation such as the formulation type, the kind of excipients and the concentration of active substance in the formulation, as well as the vascularity of

\footnotetext{
*Correspondence to: Yun, H.-I., Laboratory of Veterinary Pharmacology and Toxicology, College of Veterinary Medicine, Chungnam National University, Daejeon 305-764, South Korea. e-mail: hiyun@cnu.ac.kr.

(C)2013 The Japanese Society of Veterinary Science
}

the injection site [1]. Delis et al. demonstrated that i.m. injection of amoxicillin in the neck area of sheep resulted in more rapid absorption with a higher maximum concentration than injection in the hind limb [5]. In addition, the effect injection site was observed in horses, with a tendency for the neck area to be advantageous, mainly in terms of the rate of absorption rather than the extent of absorption $[2,7$, 8]. However, the effects of injection site on the pharmacokinetics of cefquinome have not been investigated in pigs. The aim of present study was to evaluate the effect of injection sites (neck or thigh) on the pharmacokinetic profiles of cefquinome following i.m. injection in healthy piglets.

Cefquinome sulfate as an analytical standard was purchased from Dr. Ehrenstorfer (Augsburg, Germany). Cephalexin, internal standard (IS), was purchased from SigmaAldrich Inc. (St. Louis, MO, U.S.A.). Acetonitrile (ACN) and methanol were obtained from J.T. Baker (Deventer, the Netherlands). A solid-phase extraction (SPE) plate was purchased from 3M (EmporeTM, St. Paul, MN, U.S.A.). A commercial injectable preparation of cefquinome sulfate, Cequus ${ }^{\circledR}$ (cefquinome sulfate 2.5\%, Batch No. 090528; Woogene B\&G, Hwaseong, South Korea) was obtained from a local distributor.

This study was performed using 12 healthy cross-bred (Landrace $\times$ Duroc $\times$ Yorkshire) piglets weighing 23-26 kg at 7 weeks. They were housed in boxes in pairs, fed antibiotic-free diet and provided with groundwater ad libitum throughout the period. All studies were performed according to the Guidelines for Animal Experiments of Chungnam National University (Daejeon, South Korea) and approved 
by the Animal Ethics Committee, Chungnam National University.

The study was performed using a 3-period, 3-sequence, 3-treatment, randomized crossover design with each piglet randomly allocated into three groups (i.v. or i.m. injection into the neck or thigh) of 4 animals each. One group was given i.v. injection of cefquinome at the dose of $2 \mathrm{mg} / \mathrm{kg}$ bodyweight (b.w.) into the ear vein. The other groups received an i.m. injection of the same dose into the neck area (deep into the middle third of the left cervical musculature) or thigh (semitendinosus muscle). Between periods washout intervals of 1 week were allowed. All animals were kept fasted $12 \mathrm{hr}$ before injection. Blood samples $(3 \mathrm{ml})$ were collected from the jugular vein at 0 (pre-injection), 0.016 (i.v. only) and $0.08,0.17,0.25,0.5,1,2,4,6,8$ and $12 \mathrm{hr}$ following i.v. or i.m. injection of the drug. Blood samples were collected in heparinized tubes and plasma was obtained by centrifugation. Plasma samples were stored at $-70^{\circ} \mathrm{C}$ until analysis.

The cefquinome in plasma was extracted by SPE. In brief, plasma samples $(100 \mu l)$ were added to $10 \mu l$ of IS $(10 \mu \mathrm{g} /$ $\mathrm{m} l$ ) and the samples were transferred to a pre-conditioned SPE plate with $500 \mu l$ of methanol and $500 \mu l$ of water. The plate was washed with $500 \mu l$ of water and finally, the analyte was eluted from the SPE plate with $200 \mu \mathrm{l}$ of $1 \%$ acetic acid in ACN. The extracted sample residue was transferred to $1.7 \mathrm{~m} l$ tubes and evaporated to dryness at $40^{\circ} \mathrm{C}$ under $\mathrm{N}_{2}$ gas. The residues were reconstituted with $100 \mu l$ of water and $10 \mu l$ was injected into the liquid chromatograph/mass spectrometer (LC-MS).

The plasma concentration of cefquinome was determined using an Agilent 1100 series LC/MSD (Agilent, Palo Alto, CA, U.S.A.) system. Separation was achieved on Eclips plus $\mathrm{C}_{18}$ column $(3.5 \mu \mathrm{m}, 4.6 \times 150 \mathrm{~mm}$, Agilent, Wilmington, DE, U.S.A.) with a guard column $(4 \times 3.0 \mathrm{~mm}$, Phenomenex, Torrance, CA, U.S.A.). The mobile phase consisted of A $(0.1 \%$ acetic acid and $10 \mathrm{mM}$ ammonium acetate) and $\mathrm{B}$ (ACN) with gradient elution as follows: 0-2 min, hold at 5\% B; 2-8 min, liner gradient to $25 \% \mathrm{~B}$; $8-13 \mathrm{~min}$, hold at $25 \%$ $\mathrm{B}, 13-17 \mathrm{~min}$, liner gradient to $100 \% \mathrm{~B}$ at a flow rate of 0.6 $\mathrm{m} l / \mathrm{min}$. The mass spectrometer was run in the positive mode and selective ion monitoring mode focused on cefquinome at $\mathrm{m} / \mathrm{z} 529$ and cephalexin at $\mathrm{m} / \mathrm{z} 348$.

The calibration curve was linear over the concentration of $0.02-5.0 \mu \mathrm{g} / \mathrm{m} l$ with a correlation coefficient $(r)$ greater than 0.99 . Intra-assay and inter-assay variability including precision and accuracy conformed to the requirements.

The intra-assay $(n=5)$ precision values were less than $9.7 \%$, and the accuracy values ranged from $95.3-99.8 \%$ for the QC samples. The lower LOQ for this assay was 0.02 $\mu \mathrm{g} / \mathrm{ml}$, and the upper LOQ was $5.0 \mu \mathrm{g} / \mathrm{ml}$. Intra-run and inter-run variability including precision and accuracy were consistent with the requirements in the guidelines for Bioanalytical Method Validation [11].

The pharmacokinetic parameters of cefquinome were calculated by the non-compartmental analysis using the Phoenix WinNonlin 6.1 (Pharsight, Mountain View, CA, U.S.A.). Lambda $\mathrm{z}$ is a first-order rate constant associated with the terminal (log linear) segment of the curve. It was estimated by the linear regression of the terminal data points. The terminal elimination half-life $\left(\mathrm{t}_{1 / 2 \lambda z}\right)$ was calculated by the equation $t_{1 / 2 \lambda z}=0.693 / \lambda_{z}$. The area under the plasma concentration vs. time curves for both i.v. $\left(\mathrm{AUC}_{\text {i.v. } 0 \rightarrow \infty}\right)$ and i.m. $\left(\mathrm{AUC}_{\mathrm{i}, \mathrm{m} .0 \rightarrow \infty}\right)$ studies were calculated using the trapezoid method. The area under the first moment curve $\left(\mathrm{AUMC}_{0 \rightarrow \infty}\right)$ was calculated as the product of time and drug concentration vs. time. The mean absorption time (MAT) was calculated using following equation: $\mathrm{MAT}=\mathrm{MRT}_{\text {i.v. }}-\mathrm{MRT}_{\text {i.m. }}$. The total body clearance $(\mathrm{Cl})$ was calculated using $\mathrm{Cl}=$ Dose/AUC $\mathrm{C}_{\text {i.v. }}$. and the apparent steady-state volume of distribution $\left(\mathrm{V}_{\mathrm{ss}}\right)$ was calculated as $\mathrm{V}_{\mathrm{ss}}=($ Dose $) \times(\mathrm{AUMC}) / \mathrm{AUC}^{2}$ i.v. . The time of peak concentration $\left(\mathrm{t}_{\max }\right)$ and the peak plasma concentration $\left(\mathrm{C}_{\max }\right)$ after i.m. injection were determined from direct observation of plasma concentration vs. time curve. The bioavailability $(\mathrm{F})$ of cefquinome after i.m. injection was calculated as $\mathrm{F}(\%)=\left(\mathrm{AUC}_{\text {i.m. }} / \mathrm{AUC}_{\text {i.v. }}\right) \times 100$.

Pharmacokinetic parameters are presented as mean \pm standard deviation (SD). The significances of differences among experimental groups were determined using a oneway analysis of variance (ANOVA) or the corresponding nonparametric Kruskal-Wallis test, as required. Where significant effects were found, post-hoc analysis using the Tukey's multiple comparison test or Mann-Whitney U-test was performed, and $P$ value less than 0.05 was considered statistically significant.

There were no side effects such as nausea, swelling and hardness at the injection site as well as severe pains associated with i.v. or i.m. injection of cefquinome in piglets. The mean plasma concentration vs. time curve after i.v. and i.m. injection and its pharmacokinetic parameters are shown in Fig. 1 and Table 1, respectively.

The mean $\mathrm{t}_{1 / 2 \lambda \mathrm{z}}$ and $\mathrm{Cl}$ of cefquinome after i.v. injection of cefquinome in piglets were $1.78 \pm 0.39 \mathrm{hr}$ and $0.20 \pm 0.03 \mathrm{l}$ $\mathrm{kg} / \mathrm{hr}$, respectively, which is consistent with the findings of a previous study on piglets $(1.85 \pm 1.11 \mathrm{hr}$ and $0.26 \pm 0.08 \mathrm{l} /$ $\mathrm{kg} / \mathrm{hr}$ ) [12]. This was similar to the findings for other species, the $t_{1 / 2 \lambda z}$ and $\mathrm{Cl}$ of cefquinome ranged from 0.78 to $1.64 \mathrm{hr}$ and 0.18 to $0.34 \mathrm{l} / \mathrm{kg} / \mathrm{hr}$ in sheep, rabbits, wild boars and duck indicating the rapid elimination of cefquinome after i.v. injection $[10,13,14,18,21]$. The $\mathrm{V}_{\mathrm{ss}}$ of cefquinome in this study was $0.25 \pm 0.04 \mathrm{l} / \mathrm{kg}$, which was similar to the reported values of $0.23 \mathrm{l} / \mathrm{kg}$ in calves, $0.21 \mathrm{l} / \mathrm{kg}$ in rabbits and $0.21 \mathrm{l} / \mathrm{kg}$ in horses $[10,13,19]$. The low hydrophobic nature and low pKa values for cefquinome might be one of major reasons for its limited distribution to the tissues [4].

Differences in the extent of muscle movement and the inter/intramuscular blood supply, as well as the possibility of the drug spreading within and between the muscles were thought to account for the differences in the rate and extent of drug absorption [5]. Furthermore, Firth et al. [7] demonstrated higher bioavailability following i.m. injection of penicillin $\mathrm{G}$ into the neck muscle (serratus ventralis cervicis muscle) in horse than following injection into other areas, such as the pectoral region (pectoralis descendens muscle) and the hind limb (gluteus medius and biceps femoris muscle). The effect of the injection site is more pronounced 




Fig. 1. Plasma concentration vs. time curves of cefquinome after i.v. $(\bullet)$ and i.m. [neck ( $\boldsymbol{\nabla})$, thigh (०)] injection of cefquinome at the dose of $2 \mathrm{mg} / \mathrm{kg}$ b.w. in piglets.

with the conventional formulation [5]. In this study, the bioavailability of cefquinome after i.m. injection of cefquinome into the neck muscle was slightly higher than when it was injected into thigh muscle, however, there were no significant differences between the injection sites.

When cefquinome was administered i.m. into the thigh muscle, the $\mathrm{C}_{\max }$ was slightly lower and $\mathrm{t}_{\max }$ was delayed compared to i.m. injection of cefquinome into the neck; however, these differences were not statistically significant $(P>0.05)$. Drug administration into the neck seemed to lead to greater systemic exposure $(\mathrm{AUC}=11.44 \pm 1.51 \mathrm{hr} \cdot \mu \mathrm{g} / \mathrm{m} l)$ than administration into the thigh muscle $(\mathrm{AUC}=9.29 \pm 1.18$ $\mathrm{hr} \cdot \mu \mathrm{g} / \mathrm{ml})$, but this difference was not statistically significant $(P>0.05)$. Cefquinome was rapidly and almost completely absorbed (F, $103.04 \pm 13.01 \%$ vs. $97.56 \pm 16.14 \%, P>0.05$ ) following i.m. injection into two different injection sites, which is consistent with the results in ducks, rabbits, wild boars and sheep [10, 14, 18, 21]. In addition, this result was similar to that in a previous report in piglets after a single i.m. injection of cefquinome sulfate oil formulation at neck muscle [12]. The $t_{1 / 2 \lambda z}$ of cefquinome after i.m. injection into the neck muscle in this study was $1.57 \pm 0.23$ vs. $1.56 \pm 0.02$ $\mathrm{hr}$, which was shorter than what was previously reported in piglets $(4.36 \pm 2.35 \mathrm{hr})$, but closer to the values obtained in wild boars $(1.41 \pm 0.31 \mathrm{hr})[12,14]$.

After i.m. injection into different injection sites in horses, cattle and sheep, the absorption and bioavailability of some antibacterial agents decreased considerably [5, 7, 8]. Accurate estimation of the differences in the rate and extent of absorption of cefquinome following i.m. injection into different injection sites, neck and thigh, could lead to a correct selection of an ideal injection site. In the present study, there were no statistically significant differences between the pharmacokinetic profiles of cefquinome injected into different sites in piglets. Meanwhile, Von Donkersgoed et al. [19] demonstrated that reducing the volume of the antimicrobial agents administered at a given intramuscular injection site
Table 1. Pharmacokinetic parameters of cefquinome determined after intravenous and intramuscular (neck and thigh) injection of cefquinome at a dosage of $2 \mathrm{mg} / \mathrm{kg}$ b.w. in piglets (mean $\pm \mathrm{SD}$ )

\begin{tabular}{lcrr}
\hline $\begin{array}{l}\text { Pharmacokinetic } \\
\text { parameters (Unit) }\end{array}$ & i.v. & i.m. (neck) & i.m. (thigh) \\
\hline$\lambda \mathrm{z}(1 / \mathrm{hr})$ & $0.40 \pm 0.07$ & $0.45 \pm 0.06$ & $0.45 \pm 0.06$ \\
$\mathrm{t}_{1 / 2 \lambda z}(\mathrm{hr})$ & $1.78 \pm 0.39$ & $1.57 \pm 0.23$ & $1.56 \pm 0.02$ \\
$\mathrm{AUC}(\mathrm{hr} \cdot \mu \mathrm{g} / \mathrm{m} l)$ & $10.19 \pm 1.49$ & $11.44 \pm 1.51$ & $9.29 \pm 1.18$ \\
$\mathrm{AUMC}\left(\mathrm{hr}^{2} \cdot \mu \mathrm{g} / \mathrm{m} l\right)$ & $12.65 \pm 1.67$ & $24.03 \pm 6.85$ & $19.19 \pm 4.08$ \\
$\mathrm{t}_{\max }(\mathrm{hr})$ & & $0.38 \pm 0.14$ & $0.42 \pm 0.13$ \\
$\mathrm{C}_{\max }(\mu \mathrm{g} / \mathrm{m} l)$ & & $4.62 \pm 0.31$ & $4.39 \pm 0.53$ \\
$\mathrm{~V}_{\text {ss }}(l / \mathrm{kg})$ & $0.25 \pm 0.04$ & & \\
$\mathrm{Cl}(l / \mathrm{hr} / \mathrm{kg})$ & $0.20 \pm 0.03$ & & \\
$\mathrm{MRT}(\mathrm{hr})$ & $1.24 \pm 0.03$ & $2.07 \pm 0.29$ & $2.05 \pm 0.21$ \\
$\mathrm{MAT}(\mathrm{hr})$ & & $0.68 \pm 0.06$ & $0.72 \pm 0.19$ \\
$\mathrm{~F}(\%)$ & & $103.04 \pm 13.01$ & $97.56 \pm 16.14$ \\
\hline
\end{tabular}

$\lambda z$, elimination rate constant associated with the terminal portion of the curve; AUC, area under the concentration-time curve from 0 to infinity; AUMC, area under the first moment concentration-time curve; $t_{1 / 2 \lambda}$, terminal half-life; $t_{\max }$, time of peak concentration; $C_{\max }$, peak plasma concentration; $\mathrm{V}_{\mathrm{ss}}$, the apparent steady-state volume of distribution; $\mathrm{Cl}$, total body clearance; MRT, mean residence time; MAT, mean absorption time; F, absolute bioavailability.

considerably diminished the extent of tissue damage in cattle. In the present study, any side effects related to injection sites were not observed. However, further studies involving repeated doses of cefquinome at both muscle injection sites (neck and thigh), will be necessary to determine which injection sites significantly reduces the incidence or severity of injection site reactions.

In conclusion, the pharmacokinetics of cefquinome were not significantly affected by the injection site into different sites (neck and thigh) in piglets. The AUC and $\mathrm{C}_{\max }$ for both injection sites were similar, indicating that there were no differences or only small differences in absorption and bioavailability. Further studies will be needed to determine the incidence or severity of injection site reactions following repeated administration of cefquinome into both injection sites.

\section{REFERENCES}

1. Baggot, J. D. 2008. The bioavailability and disposition of antimicrobial agents in neonatal animals. pp. 252-266 In: The Physiological Basis of Veterinary Clinical Pharmacology, 1st ed. Blackwell Sciences Ltd., Oxford.

2. Boyd, J. S. 1987. Selection of sites for intramuscular injections in the neck of the horse. Vet. Rec. 121: 197-200. [Medline] [CrossRef]

3. CVMP. 1999. Cefquinome (extension to pigs): Summary Report (2). EMEA/MRL/545/99-final, European Agency for the Evaluation of Medicinal Products, London.

4. CVMP. 1995. Cefquinome: Summary Report. EMEA/ MRL/005/95, European Agency for the Evaluation of Medicinal Products, London.

5. Delis, G., Batzias, G., Theodosiadou, E., Kounenis, G. and Koutsoviti-Papadopoulou, M. 2009. Influence of the injection site on the pharmacokinetics of amoxicillin after intramuscular 
administration of a conventional and a long-acting formulation in sheep. J. Vet. Pharmacol. Ther. 32: 457-464. [Medline] [CrossRef]

6. Ehinger, A. M., Schmidt, H. and Kietzmann, M. 2006. Tissue distribution of cefquinome after intramammary and "systemic" administration in the isolated perfused bovine udder. Vet. J. 172: 147-153. [Medline] [CrossRef]

7. Firth, E. C., Nouws, J. F., Driessens, F., Schmaetz, P., Peperkamp, K. and Klein, W. R. 1986. Effect of the injection site on the pharmacokinetics of procaine penicillin $\mathrm{G}$ in horses. Am. J. Vet. Res. 47: 2380-2384. [Medline]

8. Giguère, S., Sturgill, T. L., Berghaus, L. J., Grover, G. S. and Brown, S. A. 2011. Effects of two methods of administration on the pharmacokinetics of ceftiofur crystalline free acid in horses. J. Vet. Pharmacol. Ther. 34: 193-196. [Medline] [CrossRef]

9. Guérin-Faublée, V., Carret, G. and Houffschmitt, P. 2003. In vitro activity of 10 antimicrobial agents against bacteria isolated from cows with clinical mastitis. Vet. Rec. 152: 466-471. [Medline] [CrossRef]

10. Hwang, Y. H., Song, I. B., Lee, H. K., Kim, T. W., Kim, M. S., Lim, J. H., Park, B. K. and Yun, H. I. 2011. Pharmacokinetics and bioavailability of cefquinome in rabbits following intravenous and intramuscular administration. J. Vet. Pharmacol. Ther. 34: 618-620. [Medline] [CrossRef]

11. Korean Animal, Plant and Fisheries Quarantine and Inspection Agency. 2011. The Guideline of Residue Test for Veterinary Drugs, No. 2011-16, Korean Animal, Plant and Fisheries Quarantine and Inspection Agency, Anyang (in Korean).

12. Li, X. B., Wu, W. X., Su, D., Wang, Z. J., Jiang, H. Y. and Shen, J. Z. 2008. Pharmacokinetics and bioavailability of cefquinome in healthy piglets. J. Vet. Pharmacol. Ther. 31: 523-527. [Medline] [CrossRef]

13. Limbert, M., Isert, D., Klesel, N., Markus, A., Seeger, K., Seibert, G. and Schrinner, E. 1991. Antibacterial activities in vitro and in vivo and pharmacokinetics of cefquinome (HR 111V), a new broad-spectrum cephalosporin. Antimicrob. Agents Che- mother. 35: 14-19. [Medline] [CrossRef]

14. Liu, B., Zhang, C., Zhang, X., Yang, S., Yu, J., Sun, J. and Liu, Y. 2012. Pharmacokinetics and bioavailability of cefquinome in crossbred wild boars. J. Vet. Pharmacol. Ther. (in press) [Medline] [CrossRef]

15. Murphy, S. P., Erwin, M. E. and Jones, R. N. 1994. Cefquinome (HR 111V). 1994. In vitro evaluation of a broad-spectrum cephalosporin indicated for infections in animals. Diagn. Microbiol. Infect. Dis. 20: 49-55. [Medline] [CrossRef]

16. Schmidt, H., Philipp, H., Hamel, U. and Quirke, J. F. 1998. Treatment of acute respiratory tract diseases in cattle with Bisolvon in combination with either enrofloxacin, cefquinome, ceftiofur or florfenicol. Tierarztl. Prax. Ausg. G. Grosstiere Nutztiere 26: 127-132. [Medline]

17. Suhren, G. and Knappstein, K. 2003. Detection of cefquinome in milk by liquid chromatography and screening methods. Anal. Chim. Acta 483: 363-372. [CrossRef]

18. Uney, K., Altan, F. and Elmas, M. 2011. Development and validation of an HPLC method for the determination of cefquinome in sheep plasma and its application to the pharmacokinetic study. Antimicrob. Agents Chemother. 55: 854-859. [Medline] [CrossRef]

19. Van Donkersgoed, J., VanderKop, M., Salisbury, C., Sears, L. and Holowath, J. 1999. The effect of administering long-acting oxytetracycline and tilmicosin either by dart gun or by hand on injection site lesions and drug residues in beef cattle. Can. Vet. J. 40: 583-587. [Medline]

20. Winther, L., Baptiste, K. E. and Friis, C. 2011. Antimicrobial disposition in pulmonary epithelial lining fluid of horses, Part III. Cefquinome. J. Vet. Pharmacol. Ther. 34: 482-486. [Medline] [CrossRef]

21. Yuan, L., Sun, J., Wang, R., Sun, L., Zhu, L., Luo, X., Fang, B. and Liu, Y. 2011. Pharmacokinetics and bioavailability of cefquinome in healthy ducks. Am. J. Vet. Res. 72: 122-126. [Medline] [CrossRef] 